\title{
Compound Fetal Presentation
}

National Cancer Institute

\section{Source}

National Cancer Institute. Compound Fetal Presentation. NCI Thesaurus. Code C92756.

A presentation of the fetal hand or arm before the fetal vertex. 